\title{
The Typical Application of Building Energy Consumption Monitoring and Energy Management: A Case Study
}

\author{
Liang Zhao ${ }^{1}$, Ruobing Liang ${ }^{2}$ and Jili Zhang ${ }^{2}$ \\ ${ }^{1}$ Faculty of Electronic Information and Electrical Engineering, Dalian University \\ of Technology, Dalian 116024, China \\ ${ }^{2}$ Faculty of Infrastructure Engineering, Dalian University of Technology, Dalian \\ 116024, China \\ zliangdut@qq.com
}

\begin{abstract}
Building energy consumption monitoring and management system plays a vital role in the advance of building energy conservation, because it offers abundant online real time data, which are mainly used to further analyze energy saving potential and put forward a feasibility methodology for implementation. In addition to its extreme importance in decreasing energy consumption and saving costs, the platform can also help to find the anomalies of the main equipment. In this paper, we first introduce the structure of the monitoring platform, and then put forward an error analysis principle to improve the precision of heat meters. A case study is given for a building in "hot summer and cold winter" area, including the installation of various measuring meters and data verification. Finally, the energy consumption data of the building from January to December in 2013 were analyzed.
\end{abstract}

Keywords: data acquisition; energy management; energy consumption monitoring; error analysis; building energy

\section{Introduction}

Energy shortage has become increasingly serious worldwide with the rapidly growing energy use and the rapid economic development, particularly in China. China has doubled its energy consumption at an average growing rate of $3.7 \%$ during the past two decades [1]. China has also become the world's largest energy consumer according to the Statistical Review of World Energy released by British Petroleum (BP) in June 2011 [2]. Among all types of energy consumption, the one by buildings occupies about $42 \%$ in Western countries [3, 4] and about $1 / 3$ in China [5]. More importantly, the energy demand is still growing. Enhancing building energy efficiency may be a promising approach to relieve the increasingly aggravated energy problems.

Building energy-efficiency depends on two aspects. First, the designing process of a building defines its minimal energy, which can be improved by design changes such as adding insulation or using renewable energy sources. The second and more important part lies in the building's operation and maintenance, which defines how this potential is utilized [6]. Optimal building operation requires identifying the optimal trade-off between operating costs, occupant comfort, and energy-efficiency [7,8]. The operational costs and occupant comfort, which should be provided at a sufficient level, are the two key factors, while energy efficiency is often the least important, which targets at minimizing the building's energy consumption. "Know yourself and know your enemy, and you will never be defeated". The first step in optimizing a building's operational consumption is continuous monitoring of its consumption and conditions, which provides necessary data for building performance analysis and user guidance. The collection and analysis of 
building energy consumption data allows for the discovery of previously unknown building performance characteristics. It is also helpful to make a better decision about how to decrease the energy consumption rates in buildings if we can locate when and exactly where the energy consumption happens [7,9].

\section{Related Work}

Great efforts have been made to analyze how to develop a building energy consumption platform to enhance energy efficiency. A virtual 3-D environment platform was established to find out the energy waste in the physical environment [10], which could present the real-time power consumption data of loads used in buildings. From this platform, users can know exactly when and where the energy is consumed. The heating, lighting, air-conditioning and refrigeration can be measured by a networked energy management control system to understand the consumption of convenience stores [11]. Energy performance was presented from 29 hotels in Singapore, and the effects of weather conditions and the occupied rooms on the electricity consumption of the hotels were studied [12]. A reduced cost platform can not only collect energy consumption of departments in campus, but also produce load diagrams and email the users for verification [13]. An electric power energy consumption monitoring system is developed by using the Intranet in a university in Japan. The real-time data of energy consumption are displayed at the "Large-size Display Panel", which is the resource for further energy saving actions [14].

However, the problem of how to improve the quality of energy data is omitted in exiting literatures, which is a key issue to evaluate energy consumption status. Besides, most of the above methods only concern electric energy consumption but neglect the heat and water energy consumption. In addition to energy consumption monitoring, the power load forecasting is also an essential tool for energy management systems. Load management techniques allow an energy manager to reshape the building load curve and reduce the peak demand. A methodology, which can synthesize load curves and estimate the equation of the typical load curve, is proposed to predict the accumulated energy and the peak power load demand [15]. Based on this method, the energy manager can make better decision to identify energy consumption anomalies and manage energy costs. A regression model for evaluating energy consumption of housing was built with nine relevant parameters on electricity consumption, which included house status, fuel type of heating system, the existence or not of an air conditioning system and the type [16]. In order to reduce the cost of abundant sensors and meters, an estimation algorithm for virtual sensors is developed to analyze a building's energy consumption at room level [17]. However, the approach should be enhanced to become a holistic instrument because it is suitable only for estimating the heat consumption of buildings at present.

\section{System Overview}

\subsection{Building Description}

In this paper, an office building constructed in 2005 was studied. It is located in a second-tier city of Jiangsu Province with a climate of "Hot Summer and Cold Winter". The building has 20 floors aboveground and two floors underground. Its total floor area is $115,903 \mathrm{~m} 2$. Its heating, ventilating and air conditioning (HVAC) system consists of a variable refrigerant volume (VRV) air-conditioning system, and the central airconditioning system meets the requirements for offices, meeting rooms, data center and so on. In addition, dedicated outdoor air systems are installed in each floor to keep the working environment comfortable. The chilled water of the HVAC system is powered by three ground- source heat pump units, which enable the building to operate energyefficiently and help to preserve a clean environment. The building operates from 8:00 am 
to 5:00 pm Monday through Friday, while the average occupancy number per day is about 1200 people and its primary energy consumption is electricity and heat.

\subsection{System Network Structure}

The monitoring system consists of two parts: an electrical power system and a heat and cold quantity of air conditioning system. It has four main low-volt transformers. The 1\# and 2\# transformers supply power for the ground source heat pump air conditioning system, the water supply and draining system, the fire-fighting system and the main building for the administrative office. On the other hand, $3 \#$ and 4\# transformers are the power source of lighting and power system for the basement, interlayer and annex building. In each floor, we installed electric meters of all the low-volt distribution system based on the principle of subentry measurement: power, lighting, office power and HVAC system. There are total 264 electric meters installed. The cold and heat monitoring system can be divided into six regions from the aspect of manifold: the high sector and the low sector of the main building, office building, and east region 1, east region 2, and west region of the meeting room.

Figure 1 describes the construction of the monitoring system. The bottom of the figure shows various measuring meters, which are connected on the RS485 field bus hand by hand. The energy consumption data are collected by a data collector periodically, and then the data packets are sent to a data acquiring server through Ethernet. The data collector is a bridge between the server and terminal meters, which could save the energy data automatically into SD card when the network of the system is broken down, preventing information loss. The energy data are stored into the database server after further analytical processing and the final data are published by a web server, so that users can gain the information through webpage everywhere and any time (shown in the right of the figure). The energy consumption data should also be uploaded to the superior data center, with the grades of building level, which is as shown in this paper; city level, which collects the data from all the monitored buildings in the city; provincial level, which gathers the data of different cities; ministerial level, which is the summary database throughout the country.

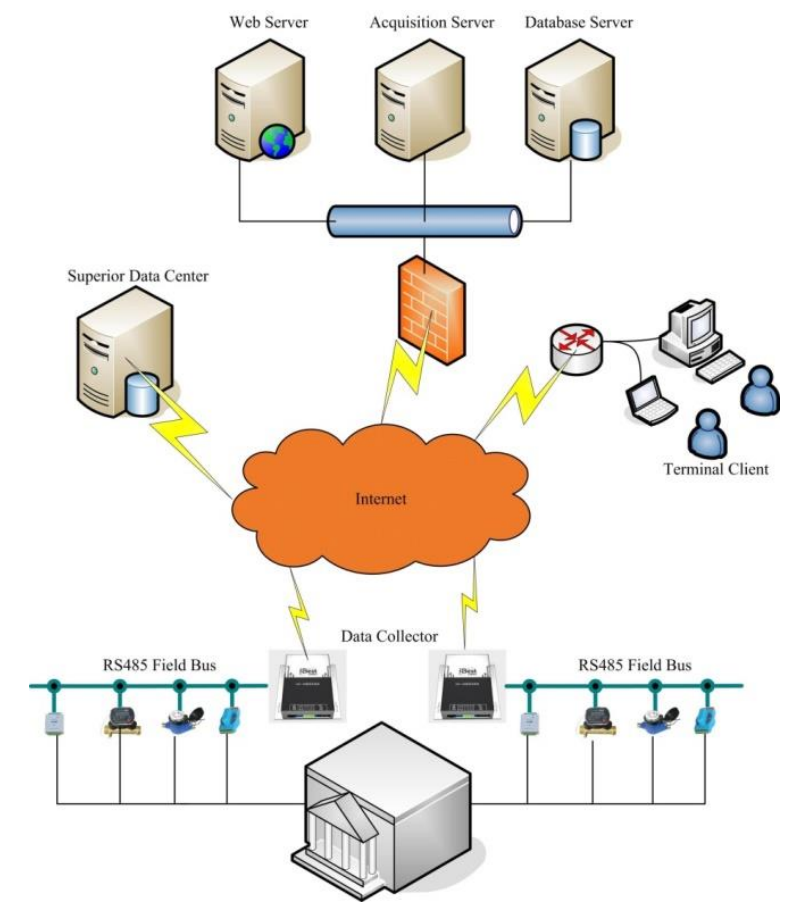

Figure 1: Structure of Building Energy Consumption Monitoring Platform 


\section{Construction of Energy Consumption Platform}

\subsection{Error Control Principle}

In constructing an energy consumption monitoring system platform, the first step is the error analysis of sensor meters, which is neglected in most exiting literatures, however. This step guarantees the quality of data collected from the meters installed in remote buildings. It is essential to study the data precision model based on the accuracy of the error analysis method. Basically, the measurement error comes from two aspects: direct and indirect measurement errors. The indirect measurement error should be calculated by a correlation function and the value measured through direct measurement. Here, the heat metering instrument is taken as an object to analyze the principle of error analysis and introduce how to trade off between the cost of meters and the precision of results.

Heat quantity is calculated as follows:

$$
Q=\int_{0}^{t} F\left(T_{\text {out }}-T_{\text {in }}\right) d t
$$

where $\mathrm{Q}$ is the measured accumulative heat quantity $(\mathrm{kW}), \mathrm{F}$ is the water mass flow $(\mathrm{kg} / \mathrm{s})$, Tin and Tout are inlet and outlet enthalpies $(\mathrm{kJ} / \mathrm{kg})$, respectively, and $\mathrm{t}$ is the cumulative time (s). Clearly, the heat quantity is the integral of the product between water mass flow and temperature difference with cumulative time.

To the best of our knowledge, the mass flow is obtained from the product volume flow and density of fluid, and the parameter measured in real environment is volume flow. Hence, the heat quantity is related to volume flow and temperature. In general, the relative errors of heat meters include the part

from flow sensor: $\left(3+0.05 \frac{F_{b}}{F}\right) \%$,

from temperature sensor: $\left(0.5+3 \frac{\Delta T_{\min }}{T_{\text {out }}-T_{\text {in }}}\right) \%$,

and from calculator: $\left\{0.5+\frac{\Delta T_{\min }}{T_{\text {out }}-T_{\text {in }}}\right) \%$,

where $\Delta T_{\min }$ is the minimum outlet-inlet temperature difference $\left({ }^{\circ} \mathrm{C}\right.$, generally 3 $\left.{ }^{\circ} \mathrm{C}\right), \mathrm{F}$ is the mass flow $(\mathrm{kg} / \mathrm{s})$ ranging from 0.156 to $12 \mathrm{~m} 3 / \mathrm{h}$, and $\mathrm{Fb}$ is the normal flow $(\mathrm{kg} / \mathrm{s})$ whose typical value is $6 \mathrm{~m} 3 / \mathrm{h}$. Based on this, the total relative error of a heat meter is

$$
E_{Q}=4 \%+\frac{12}{\Delta T} \%+\frac{0.3}{F} \%
$$

Equation (2) indicates that the relative error is in negative ratio relationship not only with temperature difference $(\Delta \mathrm{T})$, but also with the flow $(\mathrm{F})$. However, the weight is 12 for $\Delta \mathrm{T}$, but only 0.3 for $\mathrm{F}$. Thus, the effect of $\Delta \mathrm{T}$ on measurement precision may be greater than F. Figure 2 shows the changing trend of relative error with $F$ under the condition of $\Delta \mathrm{Tmin}, 2 \Delta \mathrm{Tmin}$, and $3 \Delta \mathrm{Tmin}$. Clearly, the relative error of heat quantity decreases by half when the outlet-inlet temperature difference increases from $\Delta \mathrm{Tmin}$ to $3 \Delta$ Tmin. On the other hand, the relative error decreases little while $\mathrm{F}$ more than half normal value $\mathrm{Fb}$. This conclusion is helpful to select different types of heat meters, and furthermore, we can analyze the parameters of electric meters and other types of metering devices. The detailed analysis about error distribution and error control is introduced in Ref. [18]. 


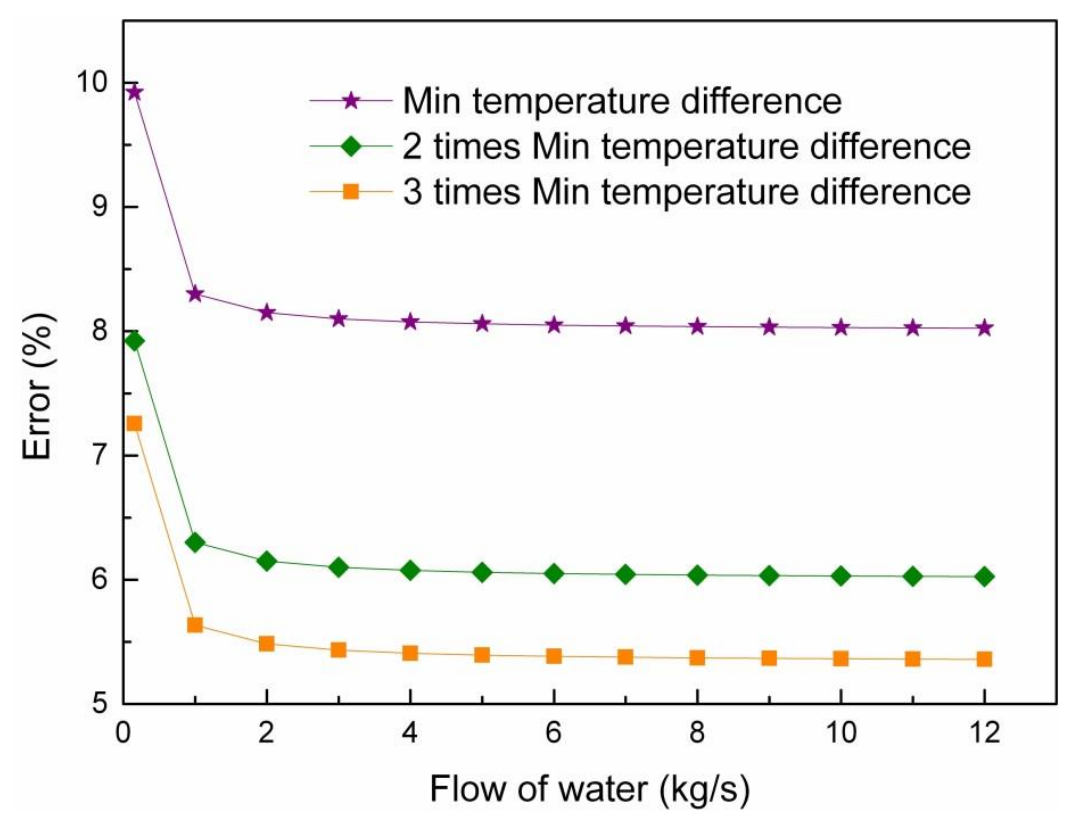

Figure 2: Relationship between Relative Measuring Error of Heat Meter and Water Flow

\subsection{Installing of Meters}

Figure 3 shows the installation of various meters and the data collector. Figure 3(a) shows the position of electric meters; the smart electric meter can measure dozens of parameters, such as the three-phase voltage, three-phase current, three-phase power, power factor and electrical quantity.

The fixation of water sensor is shown in Fig.3 (b), and the sensor is separated into two parts: the main body is placed on the pipe under manhole cover, while the power supply and communication wires are pulled to external. Besides, a pair of point-to-point wireless modules is adopted to realize the communication between the data collector and the water meter, because the distance between the two places makes it too difficult to use wired method.

Figure 3(c) presents the installation of heat meters. A heat meter is composed of three parts: calculator, flowmeter, and a pair of platinum temperature resistors. The pipe diameters range from DN65 to DN450, which makes implementation difficult. According to the error analysis principle, the temperature probe should be placed carefully to improve the measurement precision. The temperature probe is installed as follows:

Detach the waterproof rubber ring and put into the hole of the pipe;

Insert the temperature probe into the rubber ring and tighten up.

Figure 3(d) reveals the placement of the seven data collectors used in this monitoring system. The network is local area network, which offers better service than wide area network. One RS485 acquirement module of the data collector can load 64 meters through RS485 field bus, and the data collector has two acquisition modules, so the maximum load of one data collector is 128 . The store module is a 2 GB SD card, which stores the quantity of energy data up to a month. The coming data from the next month will overwrite the current data. 


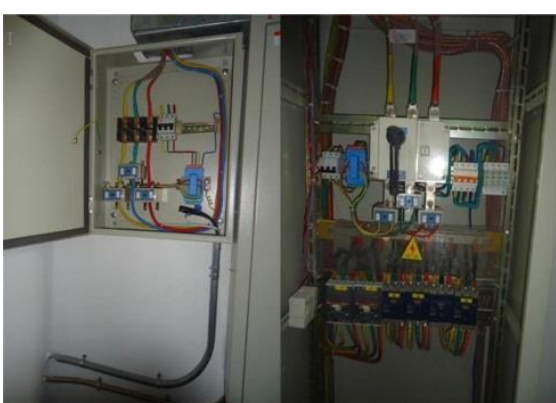

(a)

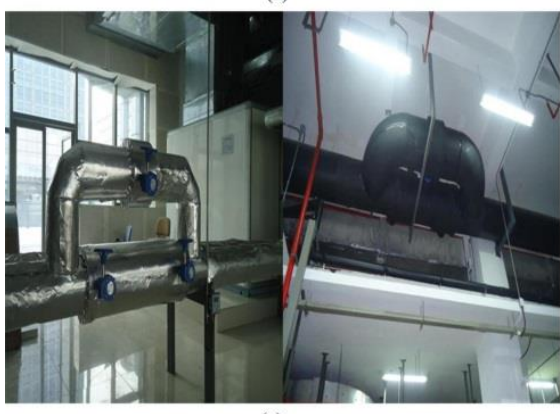

(c)

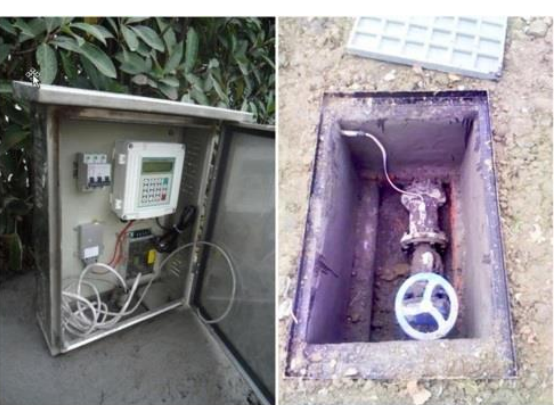

(b)

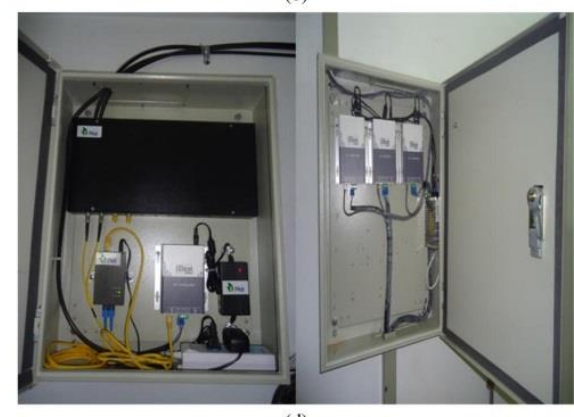

(d)

Figure 3: Installation of Measurement Meters and Data Collectors

\subsection{Data cCollection}

The primary function of the data collector is to acquire energy consumption data from the terminal meters. All the measurement meters should support RS485 field bus. However, the communication protocol and parameter settings including Baud rate and checking mode of meters are different among manufacturers. Hence, the data collector must offer several types of protocols, of which, Modbus is a more common method. The process of data collection is as follows:

The data collector connects the acquisition server to the register for communication.

The server sends the configuration of meters in the target building, which includes the manufacture of meters for helping the data collector identify the protocol of meters, the communication address and the sequence number of meters. The acquiring period information is also sent through a configuration packet, which can be modified by users.

The data collector starts collecting energy consumption data from the meters one by one periodically.

The data collector sends data packets as XML files to the server through Ethernet.

\subsection{Data Verification}

After the establishment of the monitoring platform, data verification is an indispensable step as it helps users to check if all the meters installed in the system are under good running status, so that the energy data obtained from the platform can be used for further analysis. A common method to check the value is to re-measure the branch by a standard power meter, and then compare with the data from the monitoring platform simultaneously. However, this process is time-consuming because rewiring is needed at each monitored branch. Also a hidden danger is in the wiring for line with high voltage. Besides, this method just offers an instantaneous comparison and thus may not reflect the real problem. In this paper, a quick and safe method is proposed to solve this problem. The precision of a meter can be mirrored by one parameter, such as electric quantity, although there are several parameters (voltage, current, and power). There is another meter on the electric distribution box cabinets, which records only the branch's electric quantity, the meter reading of which is collected by electrician in turn. Table 1 shows the 
comparison between the artificial reading and the data of monitoring platform at the same time. Clearly, the error is large when the reading is small, but this can be omitted because it is meaningless if the value is small. Table 1 shows that the Fresh air equipment (1-22F) is abnormal and needs further verification.

Table 1 Data Verification of Single Meter

\begin{tabular}{|c|c|c|c|c|}
\hline Monitoring point & Artificial & System & Differe & Erro \\
\hline Aeronautical light & 1 & 1.14 & 0.14 & 14.0 \\
\hline Cooling tower pump & 1 & 0.36 & 0.64 & 64.0 \\
\hline Emergency lighting & 2 & 2.46 & 0.46 & 23.0 \\
\hline Fire pump & 2 & 1.41 & 0.59 & 29.5 \\
\hline Induced draft fan of D5 region & 2 & 1.1 & 0.9 & 45.0 \\
\hline Lighting of generator room & 2 & 2.925 & 0.925 & 46.2 \\
\hline Hot water circulating pump & 6 & 5.115 & 0.885 & 14.7 \\
\hline Drinking water circulator & 9 & 9.26 & 0.26 & 2.89 \\
\hline Heat $\operatorname{Pump}(1,3)$ & 31 & 30.3 & 0.7 & 2.26 \\
\hline Plaza lighting(south) & 36 & 34.95 & 1.05 & 2.92 \\
\hline Passenger elevator & 56 & 55.53 & 0.47 & 0.84 \\
\hline Interlayer lighting & 75 & 73.665 & 1.335 & 1.78 \\
\hline $\mathrm{AC}$ of admin center(4F) & 84 & 80.52 & 3.48 & 4.14 \\
\hline Cooling pump & 210 & 208.88 & 1.12 & 0.53 \\
\hline Complaint center & 272 & 266.3 & 5.7 & 2.10 \\
\hline Fresh air equipment(1-22F) & 909 & 1277.28 & 368.28 & 40.5 \\
\hline Power and lighting(1-23F) & 1049 & 1038.48 & 10.52 & 1.00 \\
\hline 2\# transformer & 1305 & 1308 & 3 & 0.23 \\
\hline AC of main building (23-24F) & 1404 & 1392.24 & 11.76 & 0.84 \\
\hline 4\# transformer & 1773 & 1782 & 9 & 0.51 \\
\hline $\mathrm{AC}$ of main building $(1-11 \mathrm{~F})$ & 1831 & 1819.92 & 11.08 & 0.61 \\
\hline 3\# transformer & 2100 & 2115 & 15 & 0.71 \\
\hline Heat Pump(2) & 4611 & 4595.2 & 15.8 & 0.34 \\
\hline
\end{tabular}

\section{Results and Discussion}

The construction work of the monitoring platform started in October 2011 and was completed in December 2011. This paper intercepts the data from January to December in 2013. 


\subsection{Energy Consumption Distribution}

Figure 4 presents the percentages of energy consumption of heat, electricity and water from January to December. The data in Figure 4 are processed as follows:

$$
h_{4}=\frac{Q_{4}}{\sum_{i=1}^{12} Q_{i}} \quad i=1,2 \ldots 12
$$

where $\mathrm{h} 4$ is the percentage of April, and Q4 is the quantity of heat consumption in April. The processed data reflect the changing trends of electricity, heat and water consumption, although the data are not real values from the energy consumption monitoring platform. Figure 4 suggests that, firstly, the quantity of water consumption of each month remains essentially invarible; then, the variation trends of heat and electricity are consistent, or namely, higher energy consumption occurs in July and August, while lower energy consumption occurs in April, May and October. This is because the building is located in hot summer and cold winter region, and hence, temperature is very high in summer and the electric consumption reaches the peak in July. The smallest heat consumption occurs in October towing to two reasons. First, the National Day is in October and there is a long holiday of 7 days; second, temperature in October is crisp and cool (Fig. 5), so the use of air-condition is less.

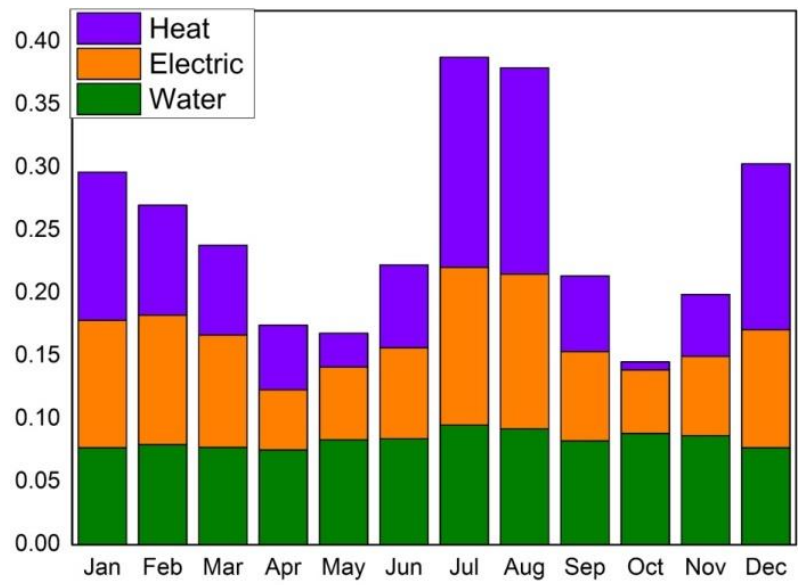

Figure 4. Energy Consumption of Each Month

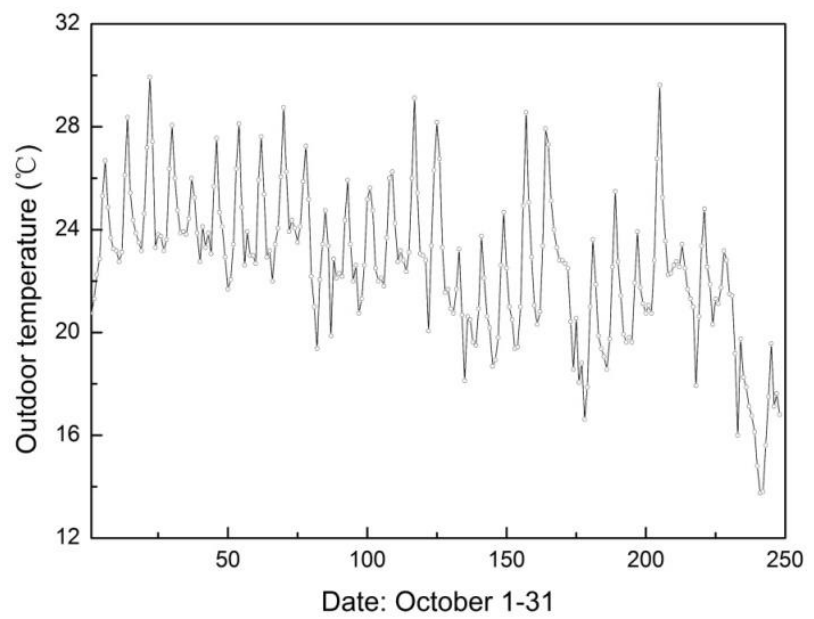

Figure 5. Temperature Change Curve in October 


\subsection{Electric Energy Consumption Analysis}

\subsubsection{Power Factor}

Power factor, which is defined as the ratio of the real power flowing to the load to the apparent power, is a primary parameter to estimate the efficiency of electrical equipment, especially for transformers. Figure 6 shows the changing curves of power factors of four transformers from 1 to 15 in August. The values of $3 \#$ and $4 \#$ transformers are almost above 0.95 , but some points of $1 \#$ and $2 \#$ transformers are under 0.90 , even to 0.80 during the monitoring period. If the power is too low, the transformer's additional loss is increasing, which will cause a huge waste of energy.

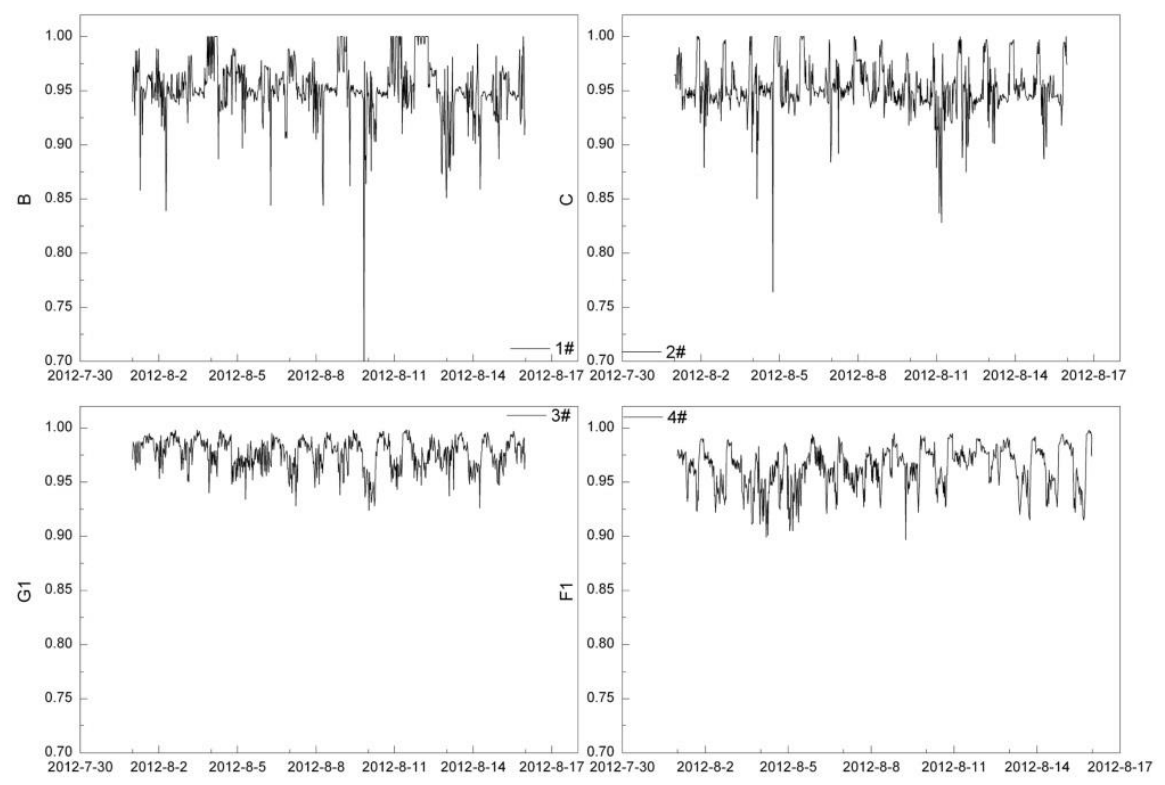

Figure 6. Power Factors of the Main Four Transformers

\subsubsection{Subentry Energy Consumption of Electricity}

The electric energy consumption of the target building is divided into lighting and socket, power, and HVAC system which includes VRV Air-Condition and groundwater source heat pump (GSHP), and special function usage which includes computer room and dining hall. Figures 7 and 8 show the quantity and the percentage the four types of energy consumption respectively. Clearly, the lighting and HVAC system contribute much, while the power and special function usage occupy a small proportion. In addition, the power quantity maintains at a low level, the same to lighting and special function usage. On the other hand, the quantity of HVAC system changes with seasons, and is maximized in July and August. Figure 9 reveals the detail percentage of subentry energy consumption of electricity in August. Clearly, the HVAC system, with a percentage of $60.95 \%$ (sum of VAR AC and GSHP) occupies the most part of electric energy consumption, followed by lighting and socket, and power (only 4.82\%). 


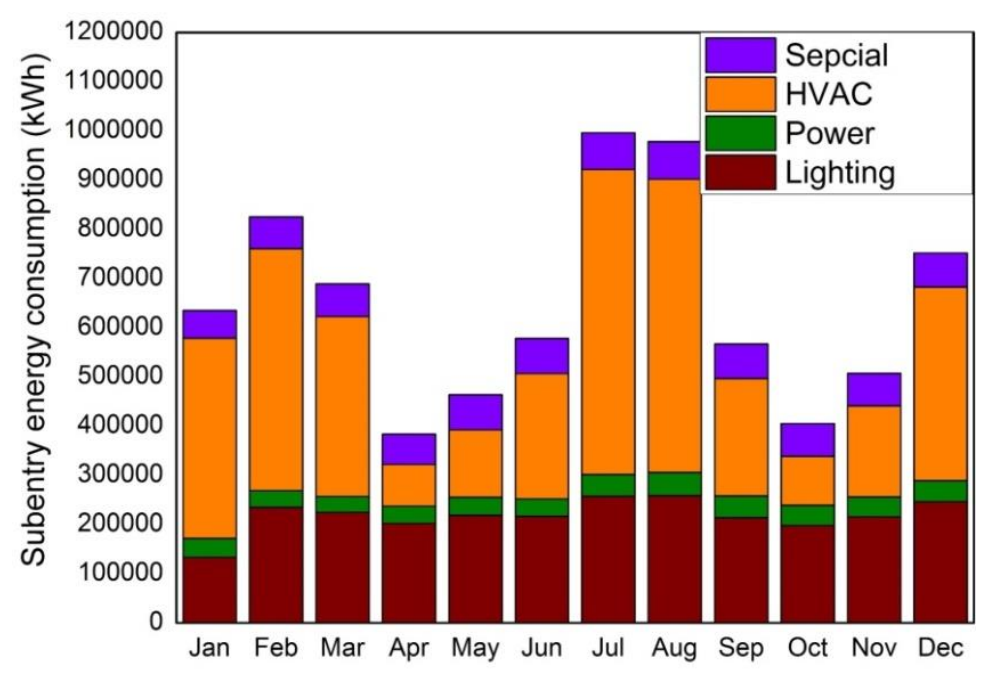

Figure 7: Subentry Energy Consumption in Each Month

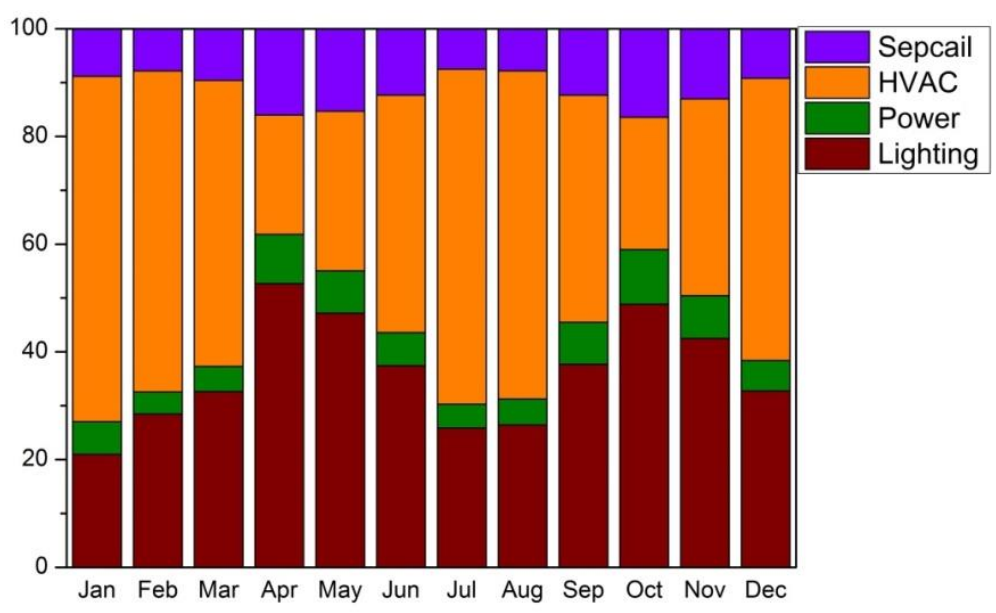

Figure 8: Percentage of Subentry Energy Consumption in Each Month

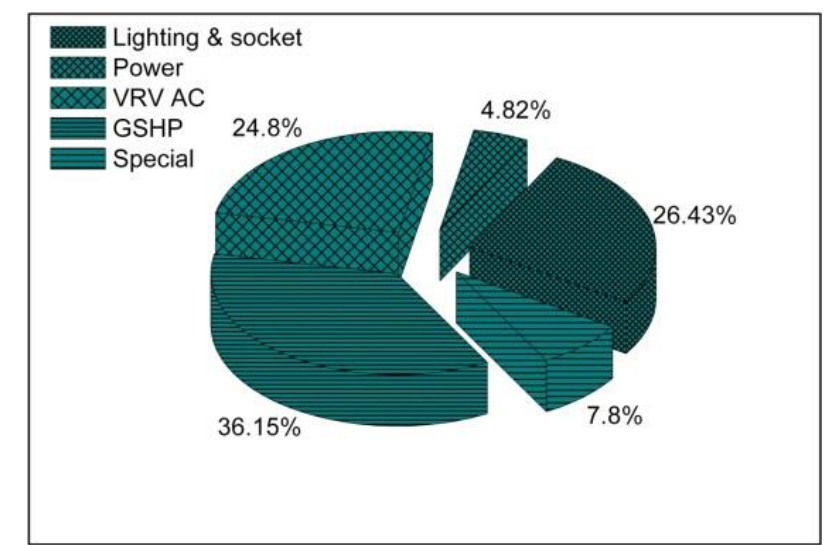

Figure 9: Electric Energy Consumption Distribution of August

\subsection{Discussion}

The energy consumption monitoring platform developed in this paper achieved three main objectives. First, it could collect the real-time energy consumption data from 
terminal equipment every 30 minutes, including water, heat, electricity and ambient temperature, and all the data are stored real-time in a database. Besides, the real-time data are processed into several time periods including hour, day, month and year, which are also stored in database. Next, the platform classifies the electrical energy by different functions and calculates the subentry energy consumption to analyze the energy consumption indexes. Finally, all the energy data can be exported in excel or pdf document.

The main sources of energy consumption in this building include water, heat and electricity, and the energy consumption results indicate that, the monthly quantity of water consumption changes very little, while the quantity of heat and electricity changes along with seasons and is maximized in July and August. Furthermore, the HVAC and lighting occupy almost $80 \%$ of electrical energy consumption. If the user forgets to turn off air conditioning after work, a single room would consume $20 \sim 30 \mathrm{KWH}$ electricity. After the platform is put into use, all the air conditionings of each room are turned off by remote control; if the users want to use the air conditioning, they can reopen it. By this measurement, the building may save 40,000 KWH electricity each year.

\section{Conclusion}

Accurate data are fundamental for better use of the energy consumption monitoring platform. In this paper, we propose a method by error analysis principle to solve the problem, but we should tradeoff between the precision and cost of the measurement meters. For the same reason, data verification is an essential part of the system after the platform was finished. Data analysis indicates that, the HVAC system is the main energy consumption source and has become the control object for energy saving. Further work in the next stage is to put forward an optimal strategy for implementation. Besides, energy saving is a long-term task, which relates society, family and everyone. It is should be noted that energy saving and consumption reduction should be implemented by each of us.

\section{Acknowledgments}

The present research is supported by the Dalian University of Technology Scientific research start-up funding (DUT14RC(3)123, DUT14RC(3)129).

\section{References}

[1] L. P. Lombard, J. Ortiz and C. Pout, "A review on buildings energy consumption information”, Energy and Buildings, vol. 40, no. 3, (2008), pp. 394-398.

[2] BP Company, "Statistical Review of World Energy", (2011).

[3] European Commission, "Action Plan for Energy Efficiency: Realising the Potential, Communication from the Commission”, (2006).

[4] L. Itard, F. Meijer, E. Vrins, H. Hoiting, "Building Renovation and Modernisation in Europe", State of the Art Review, (2008).

[5] Y. Jiang, "China building energy conservation stratagems study", Engineering Sciences, vol. 6, (2011), pp. 30-38.

[6] M. Levine, "Residential and commercial buildings, in: Climate Change 2007: Mitigation", Fourth Assessment Report of the Intergovernmental Panel on Climate Change, Cambridge University Press (2007), pp. 387-446.

[7] G. Augenbroe and C.-S. Park, "Quantification methods of technical building performance", Building Research and Information, vol. 33, no. 2, (2005), pp. 159-172.

[8] G. Kats, L. Alevantis, A. Berman, "The costs and financial benefits of green buildings", California's Sustainable Building Task Force, USA, (2003).

[9] Y. Kim, S. Thomas, et al., "ViridiScope Design and Implementation of a Fine Grained Power Monitoring System for Homes", Proceedings of the 11th international conference on Ubiquitous computing, (2009); Orlando, America. 
[10] M. Alahmad, W. Nader, Y. Choet, et al., "Integrating physical and virtual environments to conserve energy in buildings", Energy and Buildings, vol. 43, no. 12, (2011), pp. 3710-3717.

[11] A.-P. Wang, P.-L. Hsu, "The network-based energy management system for convenience stores", Energy and Buildings, vol. 40, no. 8, (2008), pp. 1437-1445.

[12] R. Priyadarsini, W. Xuchao and L. S. Eang, "A study on energy performance of hotel buildings in Singapore", Energy and Buildings, vol. 41, no. 12, (2009), pp. 1319-1324.

[13] A. Jorge, J. Guerreiro, P. Pereiraet, et al., "Energy Consumption Monitoring System for Large Complexes", First IFIP WG 5.5/SOCOLNET Doctoral Conference on Computing, Electrical and Industrial Systems, (2010); Costa de Caparica, Portugal, , pp. 419-426.

[14] T. Nagata, "An electric power energy monitoring system in campus using an Internet”, (2006).

[15] P. R.S. Jota, V. R.B. Silva, et al., "Building load management using cluster and statistical analyses", Electrical Power and Energy Systems, vol. 33, (2011), pp. 1498-1505.

[16] D. Ndiaye and K. Gabriel, "Principal component analysis of the electricity consumption in residential dwellings", Energy and Buildings, vol. 43, (2011), pp. 446-453.

[17] J. Ploennigs, A. Ahmed, B. Hensel, et al., "Virtual sensors for estimation of energy consumption and thermal comfort in buildings with underfloor heating", Energy and Buildings, vol. 25, (2011), pp. 688698.

[18] L. Zhao, J. Zhang, R. Liang, et al., "Modeling and Control of the Precision for the building energy consumption monitoring system”, Applied Mechanics and Materials, vol. 193-194, (2012), pp. 66-71. 